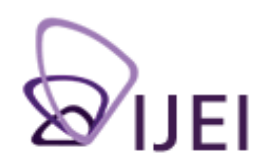

International

Journal for

Educational Integrity

\section{Culture of minimal influence: A study of Japanese university students' attitudes toward plagiarism}

\author{
Greg Wheeler \\ Sapporo Medical University \\ wheeler@sapmed.ac.jp
}

Keywords: plagiarism, culture, Japan, citation techniques, medical students

\begin{abstract}
The influence culture may have on East Asian students' attitudes toward plagiarism has been a topic of much discussion in recent years, with many scholars believing that students from this region do not view plagiarism negatively. They argue that the students have little concept of individual word ownership and consequently feel copying the works of others should not be considered a transgression. Others, however, are wary of this culture argument, and suggest that it is seemingly premised on instances in which East Asian students have plagiarised on their English writing assignments. They submit that rather than culture, the underlying cause of student plagiarism more likely stems from a fear of academic failure due to struggles with a foreign language.
\end{abstract}

Japanese students are often included among those who supposedly do not view plagiarism as morally wrong. In the present study, this theory is explored through examining data from a survey designed to gauge attitudes toward plagiarism and citation administered in 2011 to students at eight Japanese universities. Results indicate that Japanese students almost overwhelmingly view plagiarism as wrong and believe in the importance of providing citations to works they have used, although students from medical backgrounds may possibly be less concerned about the importance of citation than those from other fields. Moreover, contrary to beliefs held by both those who agree and disagree with the culture argument, results show that Japanese students seemingly receive more formal instruction regarding citation techniques than what has been commonly believed.

\section{Introduction}

Even with the popularity of detection programmes such as Turnitin, plagiarism remains rife on university campuses worldwide. At Western universities, of course, it is widely assumed that students who copy without attribution do so knowing that plagiarism is considered ethically wrong, and that they risk considerable punishment if their act is discovered.

In contrast, it is often argued that the negative connotations of plagiarism do not extend beyond the West. In particular, students from East Asian countries are said to be unaware of the notion that copying without providing sources is wrong. When these students plagiarise, supposedly they do so not with the intent to deceive. On the contrary, copying the works of others is apparently acceptable and often even encouraged.

Others are wary of this so-called culture argument, and suggest that East Asian students' attitudes toward plagiarism are similar to those held by Western (the term commonly denoting native-English speakers) students. Those refuting the culture

The International Journal for Educational Integrity is available online at: http://www.ojs.unisa.edu.au/journals/index.php/lJEI/ 
argument believe other, less 'exotic' factors such as students' struggles to thrive in a competitive (and usually English-based) academic atmosphere must be examined in order to understand why they plagiarise.

In the present study, arguments for and against the idea that plagiarism is a culture issue are first briefly discussed. Following this, the validity of the culture argument as it pertains specifically to Japan, one of the countries often expressed as having tolerant views toward plagiarism, is explored. Toward that end, students from eight Japanese universities participated in a survey that examined their reactions when encountering an instance of plagiarism and their views regarding the necessity of citation. Data gathered from this survey indicate that plagiarism is not uniformly accepted by students and indeed is considered an ethical transgression. Broader implications from the survey's results suggest that if plagiarism is regarded as immoral amongst Japanese students, scholars advocating the culture argument may need to revise their views concerning other Asian countries as well.

\section{Plagiarism as culture}

A basic tenet of the culture argument is that in East Asian societies, there is little concept of word ownership (Fallon, 2008; Leki, 1992; Pennycook, 1996; Pickering \& Hornby, 2005). Consequently, if words are considered as being owned by no one, they thereby belong to everyone. Students therefore do not hesitate to copy from the works of others because they feel they are doing nothing wrong by doing so. Moreover, since language belongs to everyone, citing the original authors is unnecessary.

Additionally, scholars argue that in East Asia, the importance of Confucian ideals plays a significant role in attitudes toward the necessity of citation (Lund, 2004; Pennycook, 1996). According to this argument, in East Asia one's elders or superiors are revered and as such, copying the works of noted scholars is a demonstration of respect. Rather than plagiarism, using the original language should be more accurately viewed as homage. Moreover, providing citation is unnecessary and may even be considered an insult in that it implies the possibility readers do not recognise the original author.

These factors are often cited when explaining attitudes toward plagiarism in Japan specifically. Sowden (2005) argues that ideas in Japan are seen as belonging to the community rather than individuals, resulting in attitudes toward plagiarism that differ from those in the West. Dryden (1999) claims that Confucian ideals established in Japan hundreds of years ago contradict the idea of individual ownership, leading to an atmosphere in which plagiarism thrives. (It should be noted that the argument that Japan is a society heavily influenced by Confucianism is a tenuous one at best.) $\mathrm{He}$ suggests that plagiarism is mostly a nonissue to the Japanese who believe that "the tendency to copy freely from published sources seems only natural" (Dryden, 1999, p. 83).

In contrast, critics of the culture argument such as Liu (2005) argue that the plagiarism as culture conclusion is erroneously reached based on incidents in which non-native English speaking students have plagiarised on their English assignments. Rather than culture, they believe these students plagiarise due to their struggles to write in a foreign language. Hyland (2001), for example, describes students who feel they must plagiarise in order to bridge the distance between themselves and more advanced students. Abasi, Akbari and Graves (2006), Bretag, Horrocks and Smith (2002) and Carroll (2002) also suggest that a lack of English skills, not ignorance, is a major cause of plagiarism by students. Liu (2005) posits that Chinese students who plagiarise understand that this is considered a moral transgression, but do so regardless in order to get ahead. In short, critics contend that it is necessary to consider the possibility that it is a language barrier rather than culture that compels 
students to plagiarise. (Future studies may do well to explore the extent of plagiarism that takes place among native English speakers taking writing courses in foreign languages.) At the very least, examining students' attitudes toward plagiarism in the context of their first language is important before summarily concluding that plagiarism is enmeshed in their societal backgrounds. However, as Norris (2007) points out, there is little research that examines these students' views toward plagiarism in the context of their native language.

\section{Plagiarism in Japan: Is culture the cause?}

According to the culture argument, Japanese students mostly do not have a strong concept of word ownership. When encountering examples of plagiarism, they therefore may be unlikely to even recognise it, let alone condemn it. However, in order to ascertain attitudes Japanese students may hold toward plagiarism, it is important to approach the issue from the context of their first language. At the same time, it is also of interest to explore the possibility that student attitudes toward plagiarism differ depending on whether they are writing in their native (L1) or a foreign (L2) language. Toward this end, to examine Japanese students' attitudes toward plagiarism and citation, in the fall of 2011 a survey was created and distributed to students at eight Japanese universities. The objective for this survey was to seek information regarding four questions:

1. If presented with an example of a text including copied sentences from another source without citation, will Japanese students recognise it as plagiarism?

2. If they do recognise the plagiarism, will this affect their opinion of the text they are reading?

3. Do attitudes toward plagiarism differ depending on whether students are writing in L1 or L2?

4. Starting from secondary school, do students learn about citation techniques? If so, at what point do they first receive guidance?

Regarding this last point, to date it has been mostly accepted that in the Japanese education system, there is a lack of formal instruction regarding citation techniques provided to students. Proponents of the culture argument, such as Dryden (1999), regard this as an indication that acknowledging authors is not considered of great importance. Moreover, even those who are neutral or express doubts about culture's influence on attitudes toward plagiarism in Japan (LoCastro \& Masuko, 2002; Rinnert \& Kobayashi, 2005; Wheeler, 2009) have reported on the lack of citation technique instruction students receive.

\section{Methodology}

Among the eight participating universities, six were four-year schools, one was a twoyear programme and one institute was a medical university. From the medical university, students from both the School of Medicine, which is a six-year programme, and the School of Health-Sciences (four years) participated. Although technically both schools are part of the same university, the two programmes have almost entirely different curriculums. Students in the School of Medicine are studying to become physicians and those from Health-Sciences are future nurses or occupational or physical therapists. There are almost no overlapping classes between the two schools.

A total of 483 students participated in the survey, which was written entirely in Japanese (see Appendix A for survey's English translation) and took approximately 20 minutes to complete. Participants were informed that their replies (also in Japanese) would be anonymous. To prevent possible preconceived biases, 
participants were not told beforehand that the survey was about plagiarism, nor was the term mentioned anywhere in the actual survey. Instead, they were informed somewhat vaguely that its purpose was to explore study methodologies.

Participants initially read two passages. They were informed that the first was submitted by a Japanese university student as a homework assignment from a sociology course. (In actuality, the author and a Japanese professor wrote the passage.) The assignment was to write a short essay between 500 and 700 characters (see Appendix B for English translation) comparing American and Japanese culture. The underlying theme of the 'student' passage, which consisted of four short paragraphs, was that dissimilarities between the two countries' cultures were often overstated but that in certain instances there were significant differences. Participants then read the second passage, which they were informed was an excerpt from an actual publication (Kindaichi, 1997) that also focused on cultural differences between Japanese people and foreigners.

Two slightly different versions of the student passage were created. Both versions include sentences that were copied almost directly from the Kindaichi text (with minor changes; the word 'foreigners' in the Kindaichi passage, for example, was changed to 'Americans' in both student essays). Efforts were taken to ensure that the plagiarised sections were detectable, but not overly obvious.

Placement of the copied sentences in the two student essays differed. In one version, which was distributed to half of the participants in each class (Group A) the four sentences appeared consecutively in the second paragraph. In the other passage, received by the remaining participants (Group $B$ ), there was an effort to make the copied material slightly more challenging to detect. One of the plagiarised sentences was placed toward the beginning of the second paragraph, two sentences appeared consecutively in the third paragraph and the final sentence was in the fourth paragraph. Overall, the percentage of plagiarised text from both passages was similar; from the Group A passage, $25.61 \%$ of the total composition was plagiarised; in that distributed to Group B, copied sentences made up $26.07 \%$ of the total. One objective here was to explore whether participants would be more cognisant of plagiarised material depending on its placement in the text.

After reading the two passages, participants were asked to answer several questions, the first two of which were designed to examine whether the placement of the copied text had any influence on their reactions to the material. For the first question, participants were asked to assign a grade to the student passage. Options were 優 (yuu), which is equivalent to 'superior', 良 (ryou or 'good'), 可 (ka, 'pass') and 不可 (fuka, 'fail'). Participants were instructed not to change their answers upon reading the subsequent questions.

Question 2 examined participants' recognition of and attitudes toward the plagiarised material. For this question, they were informed that the student had copied sections from the published passage, and asked to circle one of four answers ("I did not notice the copied text", "I noticed the copied text but it had no influence on my score", "I raised my score" or "I lowered my score") pertaining to what influence this may have had on the grades they assigned. Participants circling any of the final three choices were encouraged to write a brief explanation of their answer.

The third and fourth questions aimed to gauge participants' beliefs regarding the necessity of citation. An additional objective was to examine whether they possibly held different attitudes about citation depending on whether they were writing in L1 or L2. For both questions, participants were asked to rate the importance of providing a citation when using the exact words of another author. For Question 3, they were to determine this importance in situations in which they were writing in Japanese (L1). In 
Question 4, they were asked to rate this importance when writing in a foreign language (L2). For both questions, possible answers were "Very important", "Somewhat important", "Not very important" or "Not important". Participants were asked to provide explanations if their answers to Question 4 differed from Question 3.

In Questions 5 and 6, participants were again asked to mark how important they felt providing citations were when using the works of others, but this time in situations in which they were paraphrasing, rather than using the exact language. As in Questions 3 and 4, participants were instructed to rate this importance when writing in L1 (Question 5) or L2 (Question 6).

For Question 7, participants were asked whether they had received prior guidance on how to incorporate citations into their written work, and if so, to circle all possible choices (elementary school, junior high school, high school or university) that applied regarding when such instruction had occurred.

Participants were also asked to indicate whether they were male or female (Question 8). A chi-square test (95\% confidence level) indicated no significant differences in the answers from male and female students.

\section{Results}

\section{Grades}

As seen in Table 1, the majority of grades assigned to the student from both Group A and Group B were either good or pass and fewer than $5 \%$ of either group allotted the essay a superior score. A chi-square test was conducted in order to assess whether grades from participants in Group A differed significantly from those assigned by Group B participants. Although the percentage of failing marks from Group A was nearly twice that of Group B, overall no significant differences between the two groups were found $(p=0.076)$.

Table 1:

Grade distribution tabulated by group*

\begin{tabular}{|l|l|l|l|}
\hline Grade & Group A (\%) & Group B (\%) & Total (\%) \\
\hline Superior & $11(4.37)$ & $11(4.67)$ & $22(4.55)$ \\
\hline Good & $95(37.70)$ & $105(45.45)$ & $200(41.41)$ \\
\hline Pass & $112(44.44)$ & $99(42.86)$ & $211(43.69)$ \\
\hline Fail & $34(13.49)$ & $16(6.93)$ & $50(10.35)$ \\
\hline Total & 252 & 231 & 483 \\
\hline
\end{tabular}

$x^{2}=6.881, d f=3, p=0.076$

*In two classes, students mistakenly received the Group A passage only; in one class, students received only the Group B passage. This accounts for the slight discrepancy in total participant numbers between the two groups.

\section{Influence}

As seen in Table 2, just over $12 \%$ of Group A participants answered that they had not noticed that the student copied text from the published essay, as opposed to over $22 \%$ of those from Group B, suggesting that grouping the plagiarised text together made it easier to recognise. 
Table 2:

Influence copied text had on participants' grades ("Did not notice" responses included)

\begin{tabular}{|l|l|l|l|}
\hline Influence & Group A (\%) & Group B (\%) & Total (\%) \\
\hline Did not notice & $31(12.30)$ & $52(22.51)$ & $83(17.18)$ \\
\hline Noticed but no effect & $95(37.70)$ & $92(39.83)$ & $187(38.72)$ \\
\hline Raised score & $13(5.16)$ & $12(5.19)$ & $25(5.18)$ \\
\hline Lowered score & $113(44.84)$ & $75(32.47)$ & $188(38.92)$ \\
\hline Total & 252 & 231 & 483 \\
\hline
\end{tabular}

$x^{2}=12.192, d f=3, p=0.007$

A chi-square test confirmed significant differences $(p=0.007)$ in the replies between the two groups. However, when another chi-square test was run that included data only from participants who noticed the copied text (Table 3 ), no significant differences were found in the answers between groups $(p=0.183)$.

Table 3:

Influence copied text had on participants' grades ("Did not notice" responses excluded)

\begin{tabular}{|l|l|l|l|}
\hline Influence & Group A (\%) & Group B (\%) & Total (\%) \\
\hline Noticed but no effect & $95(42.99)$ & $92(51.40)$ & $187(46.75)$ \\
\hline Raised score & $13(5.88)$ & $12(6.70)$ & $25(6.25)$ \\
\hline Lowered score & $113(51.13)$ & $75(41.90)$ & $188(47.00)$ \\
\hline Total & 221 & 179 & 400 \\
\hline
\end{tabular}

$X^{2}=3.396, d f=2, p=0.183$

Over half the participants from Group A and over 40\% from Group B who identified the plagiarism reported that this had a negative effect on their scores. In contrast, less than $6 \%$ from Group A and $7 \%$ from Group B reported that it had a positive influence. A large percentage of participants (close to $43 \%$ from Group $A$ and over half of Group B) also deemed that the copied sections did not influence their marks.

Another chi-square test was conducted (Table 4) to determine possible differences in grades assigned by participants who recognised the copied text and those who did not. The test indicated significant differences between the two groups, with participants recognising the plagiarised text tending to assign lower scores than those unaware of the copied sections. In particular, participants who recognised the plagiarism were far more likely to assign a failing grade.

Table 4:

Grades from participants noticing or not noticing copied text

\begin{tabular}{|l|l|l|l|}
\hline Grade & Noticed copied text (\%) & Did not notice (\%) & Total (\%) \\
\hline Superior & $16(4.00)$ & $6(7.23)$ & $22(4.55)$ \\
\hline Good & $154(38.50)$ & $46(55.42)$ & $200(41.41)$ \\
\hline Pass & $183(45.75)$ & $28(33.73)$ & $211(43.69)$ \\
\hline Failure & $47(11.75)$ & $3(3.61)$ & $50(10.35)$ \\
\hline Total & 400 & 83 & 483 \\
\hline
\end{tabular}

$x^{2}=12.993, d f=3, p=0.005$ 
Comments from participants who lowered their scores due to the copied text indicated a clear condemnation of the student's action. In total, 159 of the 188 participants who answered that the copied text had a negative influence on their scores provided explanations for their marks, all of which were critical of the student's action.

A total of 117 participants wrote explanations for why the copied text had no influence on their grades. Among them, the most common sentiment was that copying just a few sentences was considered permissible. This was true of participants from both groups. Other comments indicated that some participants had noticed the copied sentences, and although they believed plagiarism to be wrong, assumed that the student had cited the original work. Additionally, one participant (from Group A) believed the copied text to be merely a coincidence.

Of the approximately $5 \%$ of students who raised their scores due to the plagiarised text, the majority did so because they felt it made the student passage easier to understand. Overall, comments indicated participants' approval that the student would use information from a published work on a homework assignment.

\section{Providing citations when quoting authors}

Answers for the third and fourth questions indicated participants believed in the necessity of citing authors when using their exact words and that language mattered little in regard to this. As seen in Table 5, over $93 \%$ of participants answered that when writing in either L1 or L2, citation was very or somewhat important. A chi-square test, conducted to compare participants' answers for Questions 3 and 4, indicated no significant differences.

Table 5:

Importance of citing when using the exact language of authors when writing in $L 1$ or $L 2$

\begin{tabular}{|l|l|l|l|}
\hline Importance & L1 (\%) & L2 (\%) & Total (\%) \\
\hline Very important & $289(59.83)$ & $291(60.25)$ & $580(60.04)$ \\
\hline Somewhat important & $162(33.54)$ & $159(32.92)$ & $321(33.23)$ \\
\hline Not very important & $28(5.80)$ & $28(5.80)$ & $56(5.80)$ \\
\hline Not important & $4(0.83)$ & $5(1.04)$ & $9(0.93)$ \\
\hline Total & 483 & 483 & 966 \\
\hline
\end{tabular}

$X^{2}=0.146, d f=3, p=0.986$

Of note, although to this point participant replies from all the universities had been consistently similar, starting with Question 3 and continuing through Question 7, responses from participants in the medical university's School of Medicine diverged from those in the other fields. In Question 3, replies from the School of Medicine participants indicated that they appeared to place less emphasis on the importance of citation than did the students from the other fields (including those from the School of Health-Sciences). Table 6 compares answers for Question 3 between participants from the School of Medicine and those from other fields, and shows that nearly $14 \%$ of the former answered that citing the original work was either not important or not very important, whereas fewer than $5 \%$ of the other students answered similarly. A chi -square test determined the differences between the two groups to be significant $(p=0.0002)$. 
Table 6:

Importance of citing when using the exact language of authors when writing in L1 tabulated by participants' fields

\begin{tabular}{|l|l|l|l|}
\hline Importance & School of Medicine (\%) & Other fields (\%) & Total (\%) \\
\hline Very important & $48(44.04)$ & $241(64.44)$ & $289(59.83)$ \\
\hline Somewhat important & $46(42.20)$ & $116(31.02)$ & $162(33.54)$ \\
\hline Not very important & $13(11.93)$ & $15(4.01)$ & $28(5.80)$ \\
\hline Not important & $2(1.83)$ & $2(0.53)$ & $4(0.83)$ \\
\hline Total & 109 & 374 & 483 \\
\hline
\end{tabular}

$x^{2}=19.866, d f=3, p=0.0002$

Moreover, a chi-square test comparing the two groups' answers to Question 4 (Table 7) also showed significant differences, with the School of Medicine participants seemingly not viewing citation as imperative as did those from the other fields.

Table 7:

Importance of citing when using the exact language of authors when writing in L2 tabulated by participants' fields

\begin{tabular}{|l|l|l|l|}
\hline Importance & School of Medicine (\%) & Other fields (\%) & Total (\%) \\
\hline Very important & $51(46.79)$ & $240(64.17)$ & $291(60.25)$ \\
\hline Somewhat important & $44(40.37)$ & $115(30.75)$ & $159(32.92)$ \\
\hline Not very important & $12(11.01)$ & $16(4.28)$ & $28(5.80)$ \\
\hline Not important & $2(1.83)$ & $3(0.80)$ & $5(1.04)$ \\
\hline Total & 109 & 374 & 483 \\
\hline
\end{tabular}

$X^{2}=14.071, d f=3, p=0.003$

\section{Providing citations when using authors' ideas}

Similar to the previous two questions, replies to Questions 5 and 6 indicated participants' belief that even when writing in one's own words, using the ideas of others, regardless of language, necessitated that citations be provided, although this was not considered quite as important as when using exact language. As seen in Table 8, regardless of whether writing in L1 or L2, nearly $80 \%$ of participants deemed it very or somewhat important to provide citations when incorporating the ideas of others in their own writing. A chi-square test indicated no significant differences in participants' answers to Questions 5 and $6(p=0.990)$.

Table 8:

Importance of citing when using the ideas of others when writing in L1 or L2

\begin{tabular}{|l|l|l|l|}
\hline Importance & L1 (\%) & L2 (\%) & Total (\%) \\
\hline Very important & $187(38.72)$ & $184(38.10)$ & $371(38.41)$ \\
\hline Somewhat important & $191(39.54)$ & $195(40.37)$ & $386(39.96)$ \\
\hline Not very important & $94(19.46)$ & $94(19.46)$ & $188(19.46)$ \\
\hline Not important & $11(2.28)$ & $10(2.07)$ & $21(2.17)$ \\
\hline Total & 483 & 483 & 966 \\
\hline
\end{tabular}

$X^{2}=0.113, d f=3, p=0.990$ 
Data here again indicated that although the majority of students from the School of Medicine believed citing was important, they did not feel it as imperative as did those from the other fields. Whether writing in L1 or L2, approximately $30 \%$ of these participants answered that citation was either not important or not very important, whereas just over $19 \%$ of those from the other fields shared this view (Tables 9 and 10). For both questions, a chi-square test demonstrated significant differences in the answers from the two groups.

Table 9:

Importance of citing when using the ideas of others when writing in $L 1$

\begin{tabular}{|l|l|l|l|}
\hline Importance & School of Medicine (\%) & Other fields (\%) & Total (\%) \\
\hline Very important & $32(29.36)$ & $155(41.44)$ & $187(38.72)$ \\
\hline Somewhat important & $44(40.37)$ & $147(39.30)$ & $191(39.54)$ \\
\hline Not very important & $31(28.44)$ & $63(16.84)$ & $94(19.46)$ \\
\hline Not important & $2(1.83)$ & $9(2.41)$ & $11(2.28)$ \\
\hline Total & 109 & 374 & 483 \\
\hline
\end{tabular}

$x^{2}=9.161, d f=3, p=0.027$

Table 10:

Importance of citing when using the ideas of others when writing in L2

\begin{tabular}{|l|l|l|l|}
\hline Importance & School of Medicine (\%) & Other fields (\%) & Total (\%) \\
\hline Very important & $33(30.28)$ & $151(40.37)$ & $184(38.10)$ \\
\hline Somewhat important & $44(40.37)$ & $151(40.37)$ & $195(40.37)$ \\
\hline Not very important & $31(28.44)$ & $63(16.84)$ & $94(19.46)$ \\
\hline Not important & $1(0.92)$ & $9(2.41)$ & $10(2.07)$ \\
\hline Total & 109 & 374 & 483 \\
\hline
\end{tabular}

$X^{2}=8.995, d f=3, p=0.029$

\section{Instruction regarding citation techniques}

Answers to the survey's seventh question indicated that the majority of students had received previous instruction in school regarding citation. Almost $85 \%$ had been taught at some point during the course of their education, most commonly upon entering university (Table 11).

Table 11:

Levels in school at which participants received citation technique guidance*

\begin{tabular}{|l|l|}
\hline School level & All participants (\%) \\
\hline None & $80(16.56)$ \\
\hline Elementary school & $15(3.11)$ \\
\hline Junior high school & $68(14.08)$ \\
\hline High school & $142(29.40)$ \\
\hline University & $306(63.35)$ \\
\hline
\end{tabular}

*Students circled all answers that applied. Percentages are determined by $n=483$

However, as seen in Table 12, there were pronounced differences in the answers from the School of Medicine participants and those from the other fields. Over half of the former answered that they had received no instruction regarding citation, whereas 
less than $7 \%$ of the latter answered similarly. Moreover, only $22 \%$ of School of Medicine participants indicated that they had been taught citation methods while in university, in contrast to those studying other fields, of whom over $75 \%$ replied that they had received such guidance.

Table 12:

Instruction regarding citation techniques classified by fields of study*

\begin{tabular}{|l|l|l|}
\hline School level & School of Medicine (\%) & Other fields (\%) \\
\hline No guidance & $56(51.38)$ & $24(6.42)$ \\
\hline Elementary school & $6(5.50)$ & $9(2.41)$ \\
\hline Junior high school & $21(19.27)$ & $47(12.57)$ \\
\hline High school & $23(21.10)$ & $119(31.82)$ \\
\hline University & $24(22.02)$ & $282(75.40)$ \\
\hline
\end{tabular}

*Students circled all answers that applied. Percentages are determined by $n=109$ (School of Medicine) and $n=374$ (Other fields).

\section{Discussion}

Replies provided by the survey participants indicate that Japanese students are able to identify instances of plagiarism and express opposition to the act. It is true that in Question 1 the majority of participants from both groups assigned grades of good or pass and there were few failing marks. However, as indicated in Table 4, average grades among participants who noticed the plagiarised text were significantly lower than those from participants not cognisant of the copied sections. Moreover, as seen in their replies to Question 2, only approximately $5 \%$ of participants viewed the copied text favorably, as opposed to more than half of the Group A participants and nearly $42 \%$ from Group B who lowered their scores. This does not support the theory that plagiarism is an accepted practice in Japan.

Certainly, a large number of participants also professed to being uninfluenced by the copied text when marking the student passage. However, even excluding the explanations from those who assumed the student had actually cited sources, there is little that suggests these participants believed plagiarism to be an acceptable practice. Rather, comments emphasised that participants' indifference stemmed from the fact that only a small portion of the original material was copied.

Furthermore, data from Questions 3 to 6 show that even participants who replied that the copied sections had no influence on their scores or caused them to raise scores believed that citation was necessary, both when using the exact language of others and when merely paraphrasing their works. Approximately $93 \%$ of participants $(174 / 187)$ who answered in Question 2 that the plagiarised text had no bearing on their scores also indicated in both Questions 3 and 4 that they believed citation was very or somewhat important when using the same words of others. Eighty-eight per cent $(22 / 25)$ of those raising their scores answered similarly. For both Questions 5 and $6,77 \%$ of those who were not influenced by the copied text on the student passage answered that citation was very or somewhat important when using the ideas of others. Among those who raised their scores, $72 \%$ replied that it was very or somewhat important.

It also appears that language, whether L1 or L2, does not have a strong influence on participants' views regarding the necessity of citation. As seen in Tables 5 and 8 , the answers provided by students to Questions 3 and 4 and then again for Questions 5 and 6 were similar. 
Among participants whose answers to Questions 3 and 4 differed, 14 deemed it more important to cite while writing in a foreign language than in Japanese. The most common reasons listed cited cultural differences between Japan and other countries or a belief that citation rules were stricter in foreign countries than in Japan.

Conversely, 15 participants believed that writing in Japanese precipitated a greater need to provide citations. Among the explanations provided for these answers, four wrote that providing citations in a foreign language was too bothersome or that they had not learned how to do so, suggesting the possibility that some Japanese students studying abroad may fail to provide citations when writing in $L 2$ not because they are unaware of the necessity, but rather because they do not understand how to do so or consider it too troublesome. Three other participants replied that their works were likely to be viewed only by other Japanese readers. They reasoned that Japanese readers would likely struggle with works written in foreign languages, and probably be unaware that copied text was being used, thereby enabling students to in effect get away without providing citations. Finally, three participants explained that it was necessary to include citations when writing in Japanese because they believed Japan to be stricter about such matters than elsewhere. This would seemingly contradict the underlying belief that plagiarism is acceptable according to Japanese culture.

Explanations from those who provided different answers for Questions 5 and 6 were similar. Seven students indicated that it was more important to provide citations when using the ideas of another when writing in L2 than L1. Four provided reasons for their views, explaining that other countries were stricter than Japan in matters of citation. Nine students believed it was more important to provide citations when writing in Japanese. Of the four who included comments, three explained that citing in a foreign language was too difficult, and the other student echoed the sentiment from above that due to comprehension difficulties, Japanese readers would not recognise that the foreign language text had been copied, making citation unnecessary.

These comments, even from those who believed citation rules were stricter outside of Japan, demonstrate student awareness of plagiarism issues. There is little sense of the idea that they condoned plagiarism, and at least a few believed rules regarding citation are stricter in Japan than elsewhere.

Perhaps the most surprising results of the survey are in regard to citation instruction. In contrast to practically all reports, the participants' replies indicate that to some extent, Japanese students are in fact provided instruction on citation techniques. Admittedly, it is difficult to ascertain how detailed this instruction may be, and the majority of students in the present study did not receive it until entering university. Nevertheless, it is telling that nearly $85 \%$ of participants - closer to $94 \%$ when excluding those from the School of Medicine - replied that they had received some manner of guidance, and casts doubt on the notion that word ownership is a concept unfamiliar to most Japanese.

Moreover, of the participants who answered that they had not received instruction on citation techniques, the replies from $85 \%$ indicated their belief that when using the exact words of others, regardless of language, citation was very or somewhat important. Sixty-six per cent answered similarly regarding situations in which authors' ideas - but not exact language - were used, suggesting that even without previous exposure to citation instruction, students feel compelled to assign credit to those whose works they have utilised.

\section{School of Medicine students' attitudes regarding citation}

Considering that the responses from School of Medicine students to the first two questions of the survey indicated an awareness level of plagiarism similar to that of the other students, their replies to the following questions, indicating that they placed less importance on the necessity of citation, were unexpected. Also surprising was the disparity in percentages between students from the School of Medicine receiving 
instruction regarding citation while in university (less than half), and those from the other fields. Nevertheless, even when taking into account these differences, there is not much evidence to suggest that the former believe plagiarism to be acceptable. A large percentage lowered the score of the student essay due to the copied text, and the vast majority did in fact indicate that citation when using the works of others, even if just paraphrasing, was important.

There are numerous studies (Cole, 2007; Das \& Panjabi, 2011; Pupovac, Bilić-Zulle, Mavrinac, \& Petrovecki, 2010) that focus on the frequency in which academic transgressions are committed by medical students. However, it would be premature to conclude here that Japanese medical students are more predisposed to accept plagiarism than other students based solely on responses from one medical school. Moreover, even if the medical students appeared to exhibit a somewhat more lenient attitude toward copying than the other students, this does not discount the fact that the majority still made clear their belief that citation was important.

\section{Conclusion}

This study primarily focuses on Japanese students' attitudes toward plagiarism and citation. However, it may be of interest to conduct similar studies in other East Asian countries, including China and Korea, which are also often described as harbouring forgiving attitudes toward plagiarism. The survey results in the present study contradict the oft-reported culture theory; it is reasonable to consider the possibility that similar surveys in other East Asian countries may do the same.

There are, of course, limitations to the study. As noted earlier, there appeared to be confusion among some participants regarding Question 2 on whether the fictitious student had included citations when submitting the homework assignment. Had a note been included in the survey stating that the student had not cited the source, this could have been avoided. However, no such information was added due to apprehension that its inclusion may have implied to participants that the student had committed some manner of transgression and even pressured those who had not actually noticed or been influenced by the plagiarism to reply that they had lowered the grade due to the student's failure to cite.

Additionally, instead of informing participants that the first passage had been submitted as a homework assignment, it may have been more appropriate to portray it as an excerpt from a published journal article. Participants' replies may have differed had they been informed that the piece they were evaluating was not a homework assignment, presumably read by only the instructor, but rather had appeared in a journal, something far more widely circulated with a much higher readership.

Nevertheless, results of the survey demonstrate a strong awareness of word ownership from Japanese university students (and incorporating the changes mentioned above may have resulted in even greater numbers of participants reacting negatively to the copied sections from the student passage). In short, there is little basis to conclude that culture has a role in Japanese students' attitudes toward plagiarism. In contrast, they feel it necessary to cite authors whose works they utilise, even when paraphrasing. Moreover, in contrast to widely held assumptions, most seem to receive some manner of citation instruction (with the School of Medicine students being a notable exception), some as early as elementary school.

To suggest that plagiarism does not occur amongst Japanese students would be naive. However, one should be wary of conclusions suggesting this occurs due to cultural influences. On the contrary, Japanese students recognise plagiarism's negative connotations, making them not altogether different from their Western counterparts. 


\section{References}

Abasi, A. R., Akbari, N., \& Graves, B. (2006). Discourse appropriation, construction of identities, and the complex issue of plagiarism: ESL students writing in graduate school. Journal of Second Language Writing, 15, 102-117.

Bretag, T., Horrocks, S., \& Smith, J. (2002). Developing classroom practices to support NESB students in information systems courses: Some preliminary findings. International Education Journal, 3(4), 57-69.

Carroll, J. (2002). A handbook for deterring plagiarism in higher education. Oxford, UK: Oxford Centre for Staff and Learning Development, Oxford Brookes University, Oxford.

Cole, A. F. (2007). Plagiarism in graduate medical education. Family Medicine, 39(6), 436-438.

Das, N., \& Panjabi, M. (2011). Plagiarism: Why is it such a big issue for medical writers? Perspectives in Clinical Research, 2(2), 67-71.

Dryden, L. (1999). A distant mirror or through the looking glass: Plagiarism and intellectual property in Japanese education. In L. Buranen \& A. Roy (Eds.), Perspectives on plagiarism and intellectual property in a postmodern world (pp. 75-85). Albany: State University of New York Press.

Fallon, F. (2008). Plagiarism and students from Asia studying in Australia and New Zealand. Paper presented at the 2008 APAIE Conference in Japan. Retrieved from http://www.isana.org.au/files/PlagAPAIE08.pdf

Hyland, F. (2001). Dealing with plagiarism when giving feedback. ELT Journal, 55, 375-381.

Kindaichi, H. (1997). Nihongo no kokoro [The heart of the Japanese language]. In NHK kokusai bunka purojekkto (Ed.), Eigo de hanasu; nihon no bunka [Japan as I see it] (pp. 10-29). (D. Kenny, Trans.). Tokyo: Kodansha Bilingual Books.

Leki, I. (1992). Understanding ESL writers: A guide for teachers. Portsmouth, NH: Boynton/Cook.

Liu, D. (2005). Plagiarism in ESOL students: Is cultural conditioning truly the major culprit? ELT Journal, 59(3), 234-241.

LoCastro, V., \& Masuko, M. (2002). Plagiarism and academic writing of learners of English. Hermes Journal of Linguistics, 28, 11-33.

Lund, J. (2004). Plagiarism: A cultural perspective. Journal of Religious \& Theological Information, 6(3-4), 93-101.

Norris, R. (2007). Dealing with plagiarism at a Japanese university: A foreign teacher's perspective. The East Asian Learner, 3(1), 1-20. Retrieved from http://cs3.brookes.ac.uk/schools/education/eal/eal-3-1/Vol3 1 norris r.pdf

Pennycook, A. (1996). Borrowing others' words: Text, ownership, memory, and plagiarism. TESOL Quarterly, 30(2), 201-230.

Pickering, J., \& Hornby, G. (2005, Nov/Dec). Plagiarism and international students: A matter of values differences? Paper presented at the ISANA: International Education Association's $16^{\text {th }}$ Annual Conference: Internationalisation-Practical Solutions: A Trans-Tasman Workout, Christchurch, NZ.

Pupovac, V., Bilic-Zulle, L., Mavrinac, M., \& Petrovecki, M. (2010). Attitudes toward plagiarism among pharmacy and medical biochemistry students - crosssectional survey study. Biochemica Medica, 20(3), 307-313.

Rinnert, C., \& Kobayashi, H. (2005). Borrowing words and ideas: Insights from Japanese L1 writers. Journal of Asian Pacific Communication, 15(1), 31-56.

Sowden, C. (2005). Plagiarism and the culture of multilingual students in higher education abroad. ELT Journal, 59(3), 226-233.

Wheeler, G. (2009). Plagiarism in the Japanese universities: Truly a cultural matter? Journal of Second Language Writing, 18(1), 17-29. 


\section{Appendix A: Translation of Survey Questions}

1. Please assign a grade to the passage.
a) Superior
b) Good
c) Pass
d) Fail

2. The passage submitted by the university student sometimes uses the same sentences as those in the published passage. What influence did this have on your grade? (If answering b, c or d, please explain your reason.)

a) I did not notice the similar text so there was no influence.

b) I noticed, but was not influenced.

c) I raised my score.

d) I lowered my score.

Reason (if answering $b-d$ ):

3. When using the exact language of another author while writing in Japanese, rate the importance of providing a citation.
a) Very important.
b) Somewhat important.
c) Not very important.
d) Not important.

4. When using the exact language of another author while writing in a foreign language, rate the importance of providing a citation. (If your answer differs from Question 3, please explain the reason.)
a) Very important.
b) Somewhat important.
c) Not very important.
d) Not important.

Reason (if applicable):

5. When using your own words to express the ideas of another author while writing in Japanese, rate the importance of providing a citation.
a) Very important.
b) Somewhat important.
c) Not very important.
d) Not important.

6. When using your own words to express the ideas of another author while writing in a foreign language, rate the importance of providing a citation. (If your answer differs from Question 5 , please explain the reason.)
a) Very important.
b) Somewhat important.
c) Not very important.
d) Not important.

Reason (if applicable): 
7. Have you had any previous instruction on citation techniques? If yes, please select all answers below that apply regarding when such instruction was received.
a. No.
b. Yes, in elementary school.
c. Yes, in junior high school.
d. Yes, in high school.
e. Yes, in university.

8. Sex: Male Female

\section{Appendix B: Translation of student essays. (Copied Kindaichi text is italicized)}

Group A: It is often said that Japanese and American cultures are very different. However, I do not think that is really true. Of course there are probably some differences, but I think most people have similar thoughts and feelings, no matter where they come from. Also, it is wrong to say that all Japanese or all Americans believe something. We are all different people. For example, concerning food, I often hear that Japanese love fish, but Americans prefer meat. Certainly, some Japanese may love fish, but I think some also really like meat. At the same time, there are many Americans who like fish more than meat.

However, I do think the way some Japanese act with friends is different than Americans. Some of the things that Japanese people say to each other in the course of their daily lives sound very strange to Americans. For instance, when we run into an acquaintance on the street, we often say, "Where are you going?" Americans may well want to answer such a question with "What difference does it make to you where I'm going? Stay out of my private life!"

The Japanese friend does not mean to be rude. This is common practice in Japan. However, it seems that sometimes Americans may value their privacy more than Japanese people.

Despite this difference, both Japanese and American people understand that friendship is important and treasure it very deeply. It's just that sometimes Americans express these feelings in ways different from the Japanese.

Group B: It is often said that Japanese and American cultures are very different. However, I do not think that is really true. Of course there are probably some differences but I think most people have similar thoughts and feelings, no matter where they come from. Also, it is wrong to say that all Japanese or all Americans believe something. We are all different people. For example, concerning food, I often hear that Japanese love fish, but Americans prefer meat. Certainly, some Japanese may love fish, but I think some also really like meat. At the same time, there are many Americans who like fish more than meat.

However, I do think the way some Japanese act with friends is sometimes different than Americans. Some of the things that Japanese people say to each other in the course of their daily lives sound very strange to Americans. For example, if two Japanese friends have plans to see a movie, but one friend has to cancel suddenly, the other friend will often ask why. This may seem very rude to Americans. 
The Japanese friend does not mean to be rude. A Japanese person who is asking such a question is inquiring as to whether or not something is wrong. If so, he will feel worried and wonder about expressing concern. This is common practice in Japan.

Japanese people carry on their daily lives with feelings of concern for each other's welfare. Of course, Americans also have these feelings; they just express them in ways different from the Japanese.

\section{Acknowledgements}

The author would like to extend thanks to those involved with the distribution of the survey and is especially grateful to Kazuhiko Yamaguchi and Ken-ichi Kamo for their invaluable help with the translation and statistical testing procedures.

\section{About the author}

Greg Wheeler has lived and taught in Sapporo, Japan since 1996. Since 2008, he has been at Sapporo Medical University, where he teaches English and Japanese literature. Prior to this, he taught at Hokkaido University, where he led a number of courses focusing on cultural stereotypes between Japan and the West. His current interests, in addition to research on plagiarism, are in examining copyright issues regarding Japanese university entrance examinations. 